\title{
The path of packaging waste in the secondary sector
}

\author{
B. A. Curran ${ }^{1}$, D. W. Dixon-Hardy ${ }^{1} \&$ C. J. Barns ${ }^{2}$ \\ ${ }^{1}$ School of Process, Environmental and Materials Engineering, \\ University of Leeds, UK \\ ${ }^{2}$ School of Mechanical Engineering, University of Leeds, UK
}

\begin{abstract}
The secondary packaging sector specified in various UK legislation states that a large sector of secondary packaging originates from supermarkets. This paper examines how supermarkets deal with secondary packaging waste that encourage recycling. Supermarkets generally have a policy to recycle cardboard, paper and plastic. Packaging is returned to a central depot and this is where the recycling or bailing occurs. Each supermarket chain has its own policy on recycling and waste disposal based on Government guidelines. Anecdotal evidence suggests that manufacturers of typical supermarket products take little interest in to what supermarkets do with their secondary packaging. This paper presents the current UK situation as to the path of supermarket packaging waste.

Keywords: packaging waste, secondary sector, supermarket, recycling, re-use.
\end{abstract}

\section{Introduction}

In the UK alone there is in the region of 400 million tonnes of waste (Chameleon Net [1]), produced each year and a quarter of which is from households, commercial and industry. The remainder is made up of construction and demolition wastes, mining and agricultural wastes, sewage sludge and dredge spoils. This is shown in Figure 1. The most favoured option for disposal of waste is to place it in landfill sites. Recently this option has been questioned as to being the best option as available landfill sites are becoming scarce. In 2003 there were around 2,300 landfills (Environment Agency [3]), and each one was in the region of 28,000 hectares, which in perspective is less than $0.2 \%$ of the land of England and Wales. 


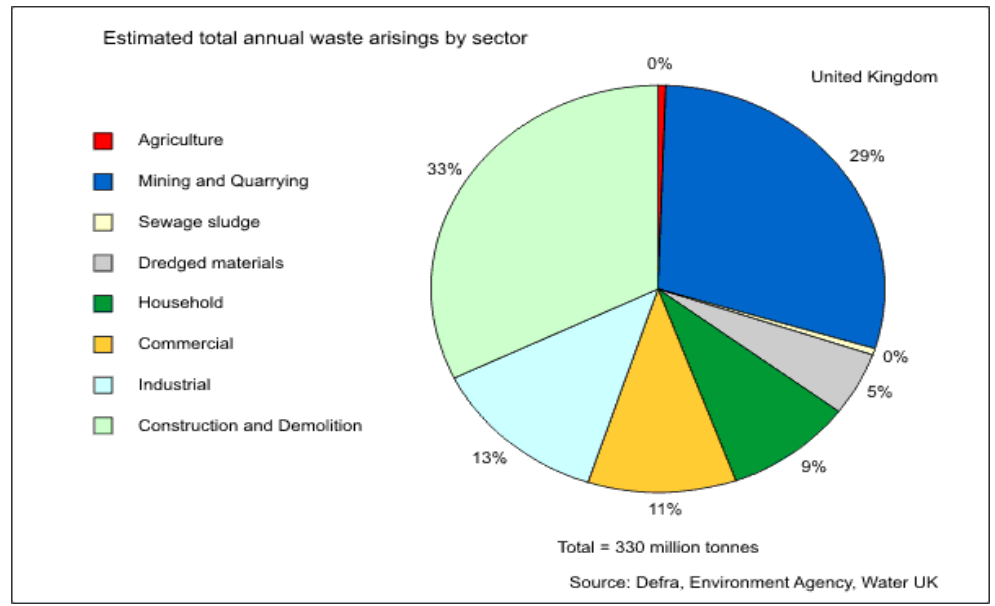

Figure 1: $\quad$ Waste production pie chart 2002/3 (Defra [2]).

The Waste Hierarchy (NWRA [4]), a pyramid diagram illustrating how to reduce waste, is used to analyse how to manage waste. The Waste Hierarchy is formed from the four principles set out in the Waste Strategy 2000 (Defra [5]), that are: -

- Reduction of waste produced

- Re-use any products where possible

- Recycle what cannot be re-used and recover energy from waste that cannot be recycled

- Disposal of the remaining waste i.e. landfill

By using the waste hierarchy (NWRA [4]), waste that is not re-used or recycled has to be disposed of and the obvious option is to send it to landfill. In 2002/03 nearly half of commercial and industrial waste was recycled (Figure 2), where $40 \%$ was sent to landfill (nearly 30 million tonnes of waste).

\section{Definitions}

Quote from (Oian et al. [7]) defining packaging:

“'Packaging' shall mean all products made of any materials of any nature to be used for the containment, protection, handling, delivery and presentation of goods, from raw materials to processed goods, from the producer to the user or the consumer. 'Non-returnable' items used for the same purposes shall also be considered to constitute packaging. "

Packaging defined above is then segregated in waste online (Environment Agency [3]), into three different categories:

- Primary packaging is handled by the consumer, as it is wrapping or a container for the product. 
- Secondary packaging term is used for larger cases or boxes used to distribute and display the primary packaged product.

- Transit packaging is used to group the packages together to ease loading and unloading of the product in bulk form, i.e. wooden pallets, board and plastic wrapping and containers.

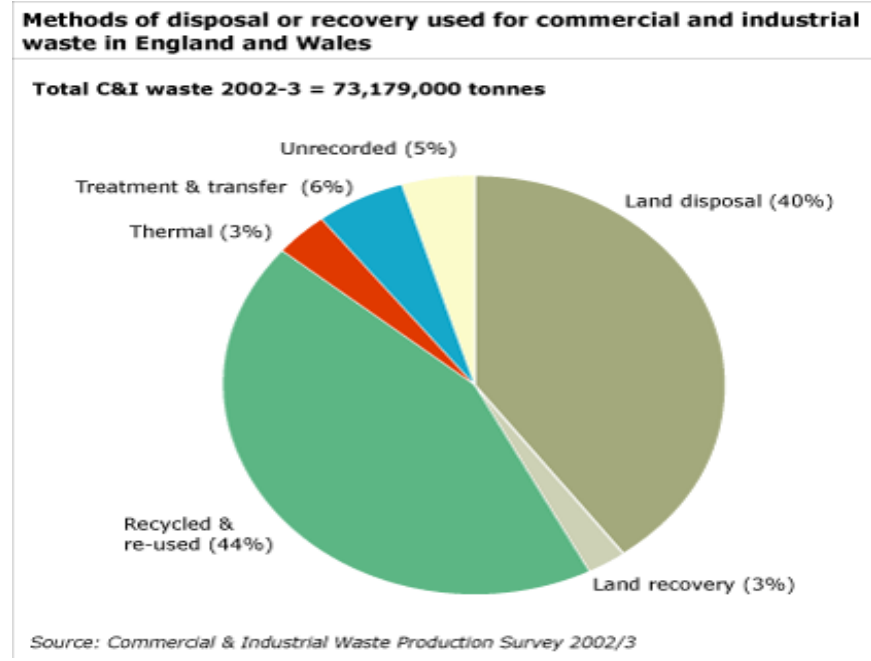

Figure 2: Industrial and commercial waste disposal (Environment Agency [6]).

Quote from (Oian et al. [7]) defining packaging waste:

“' 'Packaging waste' shall mean and packaging or packaging material covered by the definition of waste in Directive 75/442/EEC, excluding production residues.

Quote from (NWRA [4]) defining waste:

“' 'Waste' means any substance or object which the holder disposes of or is required to dispose of pursuant to the provisions of national law in force. "

Quote from (Defra [5]) defining producer:

“'Producer' means any person who, irrespective of the selling technique used, including by means of distance communication in accordance with Directive 97/7/EC of the European Parliament and of the Council of $20^{\text {th }}$ May 1997 on the protection of consumers in respect of distance contracts.

\section{Packaging and packaging waste directives}

The European Packaging and Packaging waste directive '94 (Oian et al. [7]) outlines the aims to manage packaging and packaging waste in order to prevent production of packaging waste. Additionally it aims to re-use, recycle or recover packaging to reduce the amount sent to landfill. The directive '94 (Oian et 
al. [7]) was amended in 2004 (European Parliament and Council [8]) to update the national targets for recycling of packaging waste. The directive discusses national programs and projects to reduce the impact of packaging waste by putting responsibility on producers of the packaging. The European standards are to be amended so that packaging waste will have minimal environmental impact.

The 2004 Directive (European Parliament and Council [8]) states that by $30^{\text {th }}$ June $200150 \%$ - 65\% wt packaging waste should be recycled or have energy recovered from it, and by $31^{\text {st }}$ December 2008 it should be at least $60 \%$. The targets for recovery and recycling of the packaging waste are shown in Figure 3 as minimum and maximum targets for both 2001 and 2008. Where appropriate the Directive 2004 (European Parliament and Council [8]) recommends that energy be recovered from the material rather than being recycled due to cost benefit and environmental reasons.

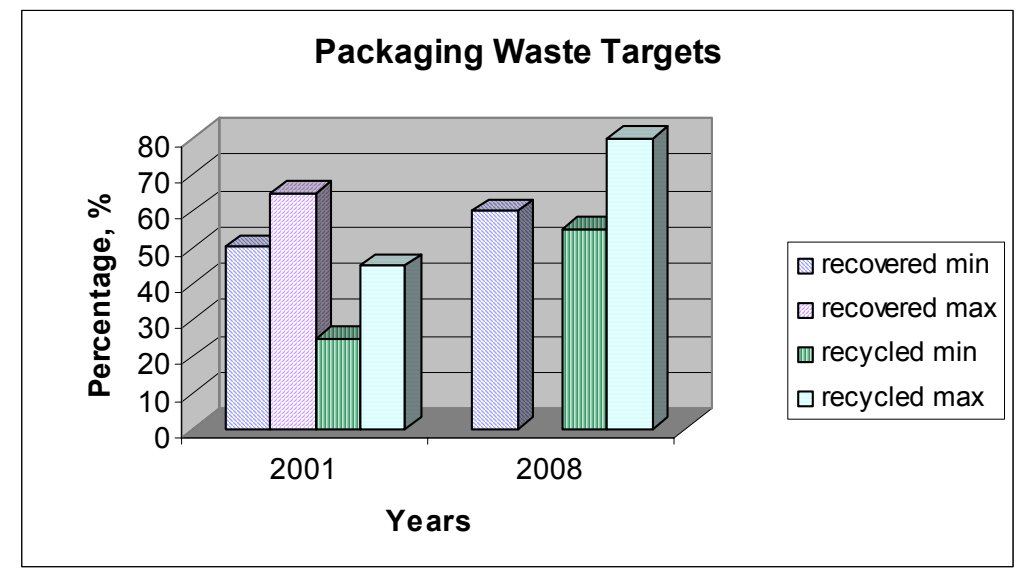

Figure 3: Packaging waste targets for 2001 and 2008 (European Parliament and Council [8]).

The minimum targets increase over the seven years from 2001 to 2008 in accordance with the advancement in recycling across the board. The recovery minimum target has increased by $10 \%$ whereas the recycling minimum target has increased by $30 \%$. Targets are set and reviewed every few years to assess if set targets are realistic, if not they can be amended accordingly. Supermarket chains are considered to be part of the producing chain of packaging waste so hence are responsible for its production. With supermarkets having to aim to achieve these targets incentives such as money for the tonnes of material that is recycled are given. This is 'accountable profit' (Morrisons [9]) for all the tonnes of packaging waste that is bailed and recycled they receive payment. They have to pay to send the remaining packaging waste to landfill.

From the pie charts in Figure 4 and Figure 5, data taken from Waste Online (Environment Agency [3]), the majority of the weight of packaging waste consists of paper and board material, $43 \%$. Comparing this to the percentage of packaging waste, plastic takes up more than half and paper and board only $25 \%$. 
This shows that paper and board can account for the most weight of packaging waste produced and plastic only $20 \%$, but can only account for a quarter of the packaging used for all products. Due to this the majority of supermarket chains only recycle plastic, and paper and cardboard. It can easily be separated and bailed and then recycled. With supermarkets paid by tonnage (Morrisons [9]) of material recycled, paper and cardboard are the obvious choice. With plastic, paper and cardboard removed from the waste, packaging waste sent to landfill should be reduced by $78 \%$ (see Figure 5).

To encourage the use of recycled material the 2004 directive (European Parliament and Council [8]) states that recycled packaging can be used to manufacture packaging and other products by improving the market conditions so these materials can be more economically viable and also review the regulations preventing the use of these materials. Raw materials are easy and readily available to use but making recycled goods cheaper will make them more attractive to packaging producers.

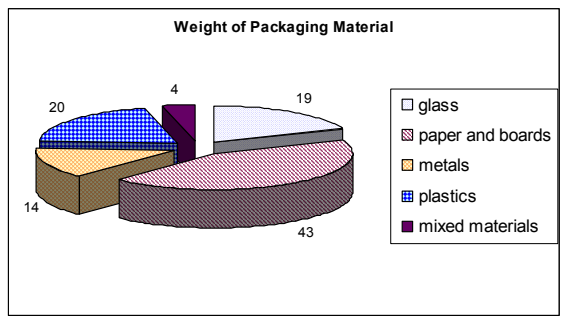

Figure 4: Weight of packaging material.

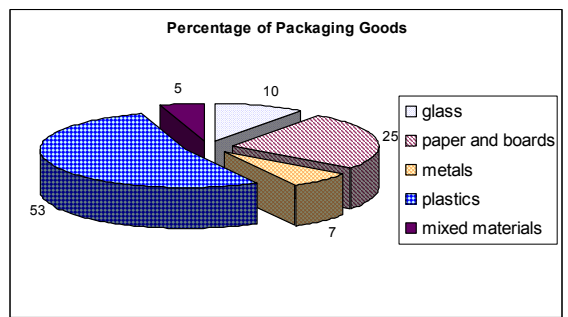

Figure 5: Percentage of packaging goods.

\section{Supermarket packaging recycling}

Seven supermarkets were chosen to investigate, of which five are in the top seven supermarkets according to TNS (BBC [16]). The supermarkets looked at were Morrisons (Morrisons [9, 13]), Asda (Asda [17]), Safeway (Morrisons [9]), Tesco (Tesco [10, 11]), Iceland (BBC [14]), the Co-op (Co-op [12]) and J Sainsbury (J Sainsbury [15]). These are the largest of the supermarket outlets in the UK and hence have the largest amount of packaging waste to dispose of. Figure 6 below shows how the supermarkets selected have increased their recycling of packaging waste and Figure 7 shows the recyclables in 2005.

From many conversations with supermarket chains it was found out that each supermarket has a responsibility to dispose of their waste wisely as they have a large amount of packaging waste cardboard and plastic. The cardboard and plastic from each supermarket chain are to be bailed and recycled. Each supermarket chain has a number of depots around the country that deliver to the supermarket outlets and the bails are returned to the corresponding depot. The larger supermarket outlets can bail the cardboard and plastic on site and then send it on to the depot but the smaller outlets send it all flat packed to be bailed when it reaches the depot. 


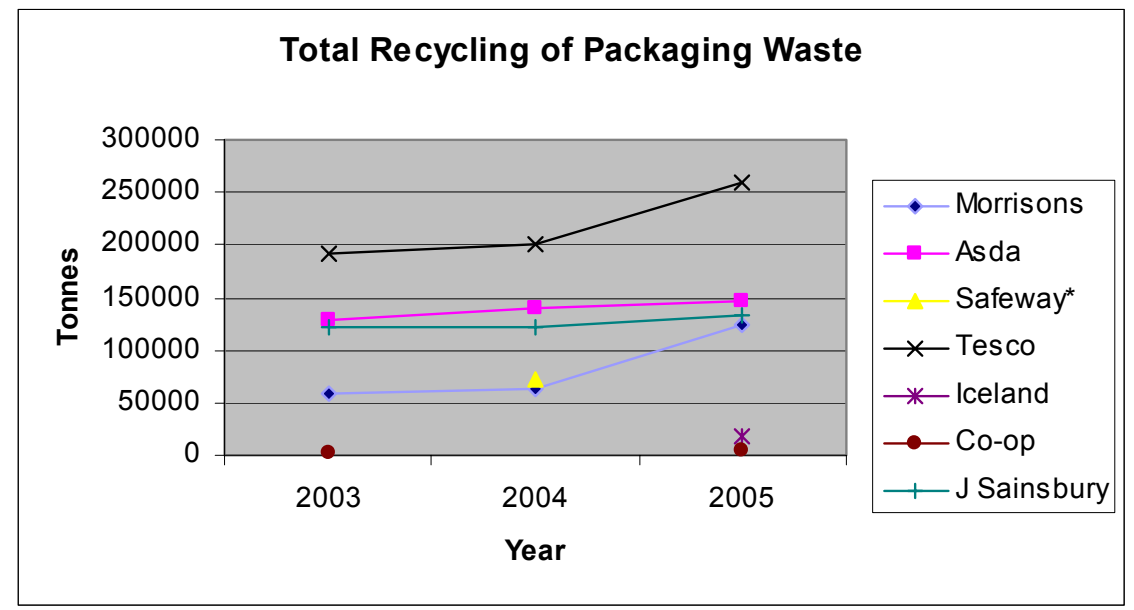

Figure 6: Total recycling of packaging waste in supermarkets.

The graph in Figure 6 shows that both Morrisons and Tesco have greatly increased the amount of packaging waste that is recycled from 2004 to 2005. They have very similar trends on the graph but Tesco has a much larger amount of recycled packaging waste because it has the greater amount of outlets due to the fact that it dominates a much larger percentage of the market (BBC [16]), around $30.6 \%$ whereas it's closest rival Asda holds only $16.6 \%$ which is nearly half that of Tesco. Safeway only has the data for 2004 because its outlet stores were purchased by Morrisons and some were sold on again to other supermarket chains.

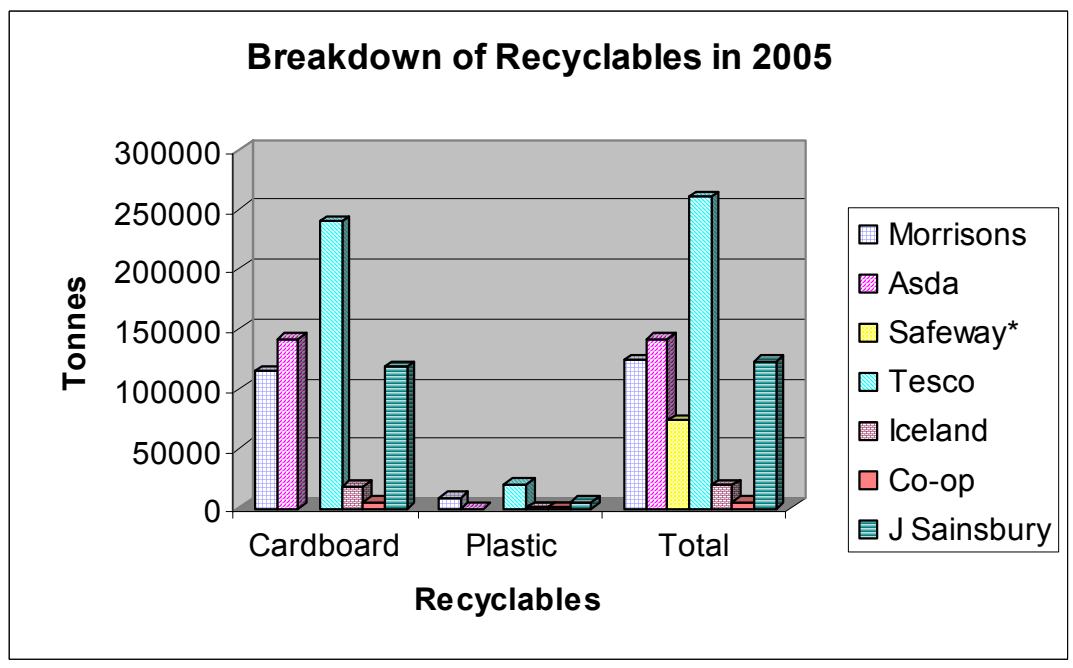

Figure 7: $\quad$ Breakdown of supermarket recyclables in 2005. 
Asda and J Sainsburys also have similar trends as well with a gentle increase in recycling each year. Figure 6 shows that all the supermarkets looked at are increasing the amount of packaging waste produced that is recycled. This shows that the supermarkets are aware of the problem with the amount of packaging waste that is sent to landfill. The breakdown of the recyclables from the supermarkets in 2005 are shown in Figure 7 except for Safeway that is for 2004 when it was bought out by Morrisons. The majority of tonnage of recyclables is cardboard (Figure 7) because plastic can have a large volume but a very low weight. Figure 4 and Figure 5 show that the majority of packaging material is plastic and the majority of packaging weight is from cardboard and paper. Therefore the two materials that the supermarkets will find most useful to recycle are plastic and cardboard because the most space in the packaging waste is taken up by the amount of plastic packaging waste and the added weight can be accounted for by the cardboard.

Figure 6 and Figure 7 both show that Tesco does the greatest amount of recycling but this is because it has the largest niche in the market. If the tonnes of packaging waste that is recycled is divided by the number of stores and the annual turnover then there will be a more realistic view as to how much relatively each supermarket is recycling. This is shown in Figure 8 and Figure 9 respectively, from this it is shown that per store Asda recycles the most packaging waste with Morrisons closely behind. Figure 8 shows that Tesco has a small amount of recycled packaging waste compared to the amount of stores that it owns. Iceland has a very small amount of recycled packaging waste but being a frozen food store it may have a different form of packaging waste to the other supermarkets, it is in the top seven supermarkets with a market share of $1.8 \%$ (BBC [16]). A more realistic view of which supermarkets are most affective at recycling is shown in Figure 9 because the tonnes of recycled packaging waste have been divided by the annual turnover of each individual supermarket.

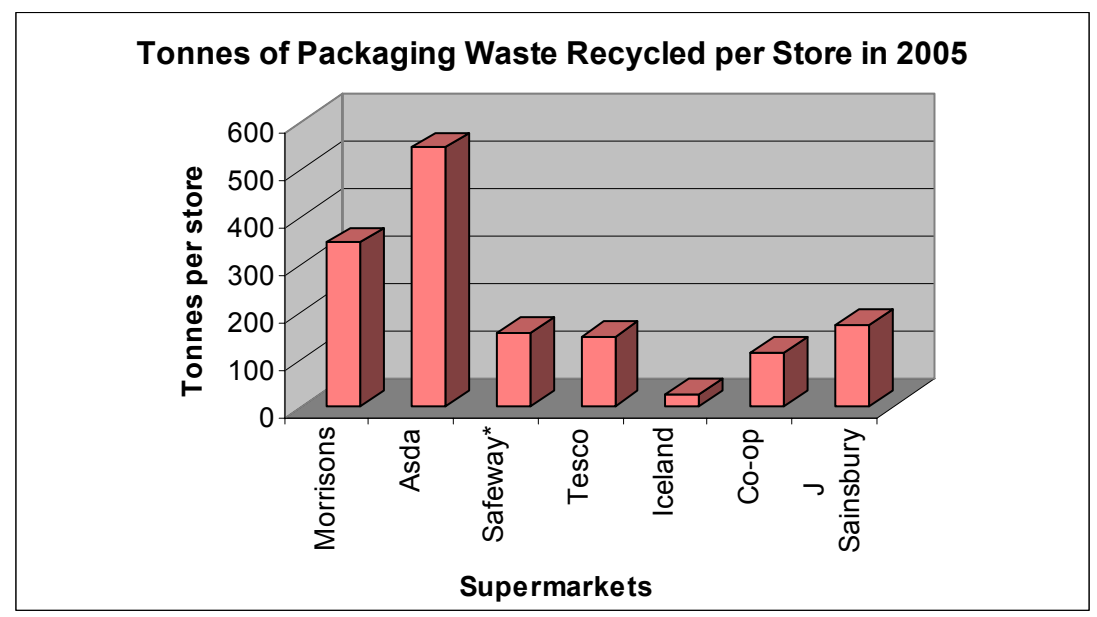

Figure 8: $\quad$ Tonnes of packaging recycled per store. 
The data was obtained from their annual reports (Morrisons [9], Tesco [10], Co-op [12], J Sainsbury's [15] and Walmart [17]). This shows the amount of packaging waste that is recycled in comparison to the annual turnover of each supermarket. From Figure 9 you can see that Morrisons has increased the amount of packaging waste that is recycled by a large amount from 2004 to 2005 compared to its annual turnover. Each supermarket has increased the amount of packaging waste that is recycled in 2005 compared to 2004 except for Asda. Asda has steadily decreased the amount of packaging waste recycled compared to the annual turnover from 2003 to 2004 and 2004 to 2005.

Figure 9 clearly shows that Morrisons has the largest increase in recycling of its packaging waste. Whilst Tesco, Co-op and J Sainsbury have only increased the recycling of their packaging waste by a small amount.

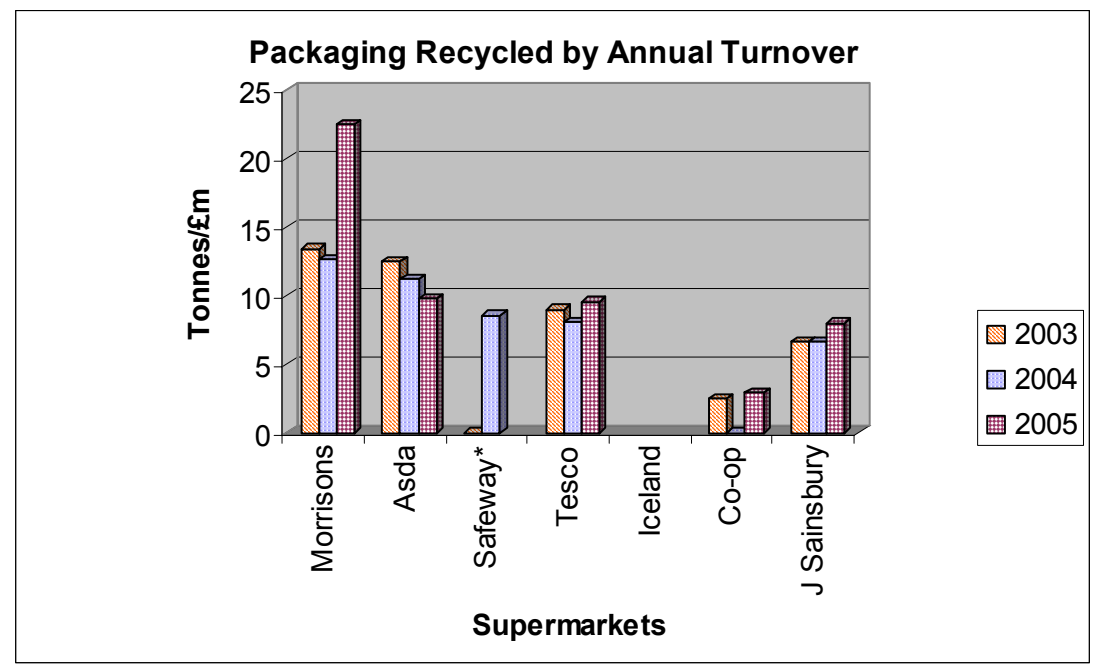

Figure 9: Tonnes of packaging recycled divided by the annual turnover.

\section{Innovative ideas}

Any packaging waste from the supermarket outlet that has been contaminated by produce has to be sent to landfill and can not be recycled. Tesco has created green trays (Tesco [10]), they are plastic trays that can be sterilised after use and then re-used. They replace the cardboard and other materials used for transporting and displaying the produce. In 2004 Tesco saved 4,000 tonnes of cardboard packaging in just replacing them with green trays. They have also developed the first degradable plastic bags (Tesco [10]). The plastic bags break down in 60 days to create carbon dioxide, water and mineral matter. There is no harmful residue unlike conventional plastic bags. They have offset 6,035 tonnes of conventional plastic carrier bags by the customers using in the region of 719 million of the degradable plastic carrier bags. They are now working with Waste 
and Resources Action Programme (WRAP) to aim to reduce product packaging by $10 \%$ whether this is in the primary, secondary or transit sector of packaging.

\section{Conclusion}

This paper shows that in the secondary sector of packaging waste the supermarkets are working towards reducing the amount of packaging waste that is produced and sent to landfill. The supermarkets looked at in this report have to pay to have the waste that they produce to be sent to landfill, so reducing the amount of waste produced would be beneficial to the supermarkets as it will reduce the cost of waste disposal. The waste is reduced by recycling the packaging waste in the form of cardboard and plastic. Comparing the supermarkets with the amount of packaging waste that is recycled difficult because each supermarket recycles in a slightly different way and all cover a different percentage of the market.

Comparing the supermarkets tonnes of packaging waste recycled per store showed which supermarkets were recycling the most in each store but it was not a fair comparison as the store sizes weren't taken into account. The larger store can have the facility to bail cardboard and plastic on site so that larger amounts of packaging waste can be recycled easily. The smaller stores may not have the room to store the packaging waste for recycling and have to throw it away. Comparing the supermarkets using their annual turnover was a fairer comparison as it showed per each £million annual turnover the supermarket made the amount of tonnes of packaging waste that was recycled was shown. This shows that the largest supermarket Tesco may have the greatest turnover and the largest sector in the market but it is not recycling as much packaging waste per £million as Morrisons or Asda. It shows that the most improved supermarket in 2005 is Morrisons. Asda, Tesco and J Sainsbury are all producing similar amounts of recycled packaging waste per £million. Further investigation is needed into why Morrisons and Tesco were able to increase the amount of packaging waste that was recycled much more than the other supermarkets.

There is a clear understanding that the supermarkets need to reduce the amount of packaging waste produced and sent to landfill. This report shows that they are working towards either reducing the amount of packaging waste produced and increasing the amount of packaging waste that is produced to be recycled. The next step is to reduce the amount of packaging waste produced. This can be done by designing packaging so that it can be re-used, or designed so that it can be disassembled and either the re-assembled to be used again or disposed of. Morrisons has offered to work on a further paper to look directly into this in their stores.

\section{References}

[1] Chameleon Net, Packaging recycling information sheet from 2004 Waste Online, Design \& development by Chameleon Net, archive 'Packaging Recycling'. Metadata Resource: 315 
[2] Defra, Environmental Agency e-Digest of Environmental Statistics. Published by Defra, Environment Agency, Water UK on 31/03/05, Data taken from the Municipal Waste Management Survey 2003/4, http:/www.defra.gov.uk/environment/statistics/index.htm

[3] Environment Agency on Landfills, What are Landfill Sites. Published by the Environment Agency - Environmental Facts and figures, http://www.environmentagency.gov.uk/yourenv/eff/1190084/resources_waste/213982/207743/?ve $\underline{\text { rsion}=1 \& l a n g=}$ e

[4] North West Regional Assembly (NWRA). Regional Planning, Transport and Sustainability. The four principals of The Waste Strategy $2000 \mathrm{Cm}$ 4693-1, ISBN 0101469322

[5] Defra, Waste Strategy 2000 for England and Wales Part 1 \& 2, Department for Environment, Food \& Rural Affairs. Cm 4693-1, ISBN 0 101469322

[6] Environment Agency - C\&I Commercial and Industrial Waste Survey 2002/2003, www.environment-agency.gov.uk

[7] Oian, X, Koerner, R. M, Gray, D.H, Geotechnical Aspects of Landfill Design and Construction. Published by Upper Saddle River, N.J. : Prentice Hall, c2002

[8] European Parliament and Council Directive 2004/12/EC of 11 February 2004 on packaging and packaging waste

[9] Morrisons 2006 Annual Report

[10] Tesco Corporate Responsibility Review 2005

[11] Tesco Corporate Responsibility Review 2004

[12] United Co-operatives Limited, Our Stakeholder Report 2005

[13] BBC, Safeway sales drop hits Morrisons, 04/06/2004 BBC News archive

[14] BBC, Iceland sales back under pressure, 25/05/2004 BBC News archive

[15] J Sainsbury Plc Annual Report 2005

[16] BBC, Tesco's market share still rising, 08/02/2006 BBC News archive

[17] ASDA WalMart Annual Report 2005 